\title{
Comportamento reológico do soro de leite desnaturado reticulado por transglutaminase em diferentes quantidades e tempos de reação
}

\author{
Rheological behavior of denatured whey crosslinked by transglutaminase on different quantities \\ and reaction time \\ Comportamiento reológico del suero de leche desnaturalizado reticulado con transglutaminasa en \\ diferentes cantidades y tiempos de reacción
}

Recebido: 24/05/2021 | Revisado: 30/05/2021 | Aceito: 01/06/2021 | Publicado: 17/06/2021

\author{
Hanndson Araújo Silva \\ ORCID: https://orcid.org/0000-0001-8914-9589 \\ Universidade Federal de Campina Grande, Brasil \\ E-mail: hanndson@gmail.com \\ Ana Paula Trindade Rocha \\ ORCID: https://orcid.org/0000-0002-0230-7394 \\ Universidade Federal de Campina Grande, Brasil \\ E-mail: ana_trindade@yahoo.com.br \\ Hugo Miguel Lisboa Oliveira \\ ORCID: https://orcid.org/0000-0002-4722-0364 \\ Universidade Federal de Campina Grande, Brasil \\ E-mail: hugom.lisboa80@gmail.com \\ Gabriel Monteiro da Silva \\ ORCID: https://orcid.org/0000-0002-8364-6661 \\ Universidade Federal de Campina Grande, Brasil \\ E-mail: silvagm839@gmail.com
}

\begin{abstract}
Resumo
Este estudo teve como objetivo avaliar o comportamento reológico da reação de catalisação do soro de leite desnaturado (WPD) com a enzima transglutaminase microbiana (TG), em função dos tempos de reação e quantidade de TG. O estudo reológico foi realizado em função das concentrações de 8, 14, 18, 22 e $26 \mathrm{U} / \mathrm{g}$ de TG e dos tempos de reação de 8, 16 e 24 horas, no qual o modelo de Ostwald-de-Waelle (Lei de potência) foi utilizado para o ajuste aos dados experimentais. $\mathrm{O}$ modelo apresentou ótimos ajustes com valores de coeficientes de determinação $\left(\mathrm{R}^{2}\right)$ maiores que 0,99 . Observou-se que a adição de TG proporcionou uma diminuição na viscosidade e aumento nas taxas de deformação. $\mathrm{O}$ aumento das tensões de cisalhamento também foi observado e as soluções apresentaram índices de comportamento de fluxo ( $\eta \mathrm{p}$ ) menores que 1, indicando que as soluções de WPD+TG apresentam comportamento de fluidos não newtonianos do tipo pseudoplástico. Verificou-se também que os tempos de reação têm influência no aumento dos índices de comportamento e na viscosidade da solução. De acordo com os resultados encontrados é possível afirmar que os tempos de reação e as quantidades de TG são determinantes em processos de obtenção de filmes e géis de qualidade, o que pode render melhores produtos após a otimização destes fatores.
\end{abstract}

Palavras-chave: Biofilmes; Propriedades reológicas; Transglutaminase; Whey protein desnaturado.

\begin{abstract}
This study aimed to evaluate the rheological behavior of catalyzing the reaction of denatured whey (WPD) with the microbial transglutaminase (TG) as a function of reaction time and amount of TG. The rheological study was performed according to concentrations of $8,14,18,22$, and $26 \mathrm{U} / \mathrm{g}$ enzyme microbial transglutaminase and reaction times of 8, 16 and 24 hours, in which the model of Ostwald-de-Waelle ( Power law) was used to adjust the experimental data. The model showed excellent adjustment with determination coefficient values $\left(\mathrm{R}^{2}\right)$ greater than 0.99 . It was observed that the addition of TG provided a decrease in viscosity and increased shear rates. The increase in shear stresses was also observed and the solutions presented flow behavior indices $(\eta p)$ less than 1 , indicating that the solutions of WPD + TG present behavior of non-Newtonian fluids of the pseudoplastic type. It was also found that the reaction times have influence on the increase in behavior index and viscosity of the solution. According to the results found, it is possible to affirm that the reaction times and the amounts of TG are decisive in the processes of obtaining quality films and gels, which can yield better products after the optimization of these factors.
\end{abstract}

Keywords: Biofilms; Rheological properties; Transglutaminase; Denatured whey protein. 


\begin{abstract}
Resumen
Este estudio tuvo como objetivo evaluar el comportamiento reológico de la reacción catalítica del suero desnaturalizado (WPD) con la enzima transglutaminasa microbiana (TG), en función de los tiempos de reacción y cantidad de TG. El estudio reológico se realizó según las concentraciones de 8, 14, 18, 22 y 26 U / g de enzima transglutaminasa microbiana y los tiempos de reacción de 8, 16 y 24 horas, en las que se utilizó el modelo de Ostwald-de-Waelle (ley de potencia) se utilizó para ajustar los datos experimentales. El modelo presentó excelentes ajustes con valores de coeficientes de determinación $\left(\mathrm{R}^{2}\right)$ superiores a 0,99. Se observó que la adición de TG proporcionó una disminución de la viscosidad y un aumento de las velocidades de deformación. El aumento de esfuerzos de corte también se observó y las soluciones presentadas índices de comportamiento de flujo ( $\eta \mathrm{p}$ ) inferior a 1, lo que indica que las soluciones de WPD + TG actual comportamiento de los fluidos no newtonianos de tipo pseudoplástico. También se encontró que los tiempos de reacción influyen en el aumento y disminución de los índices de comportamiento y en la viscosidad de la solución. De acuerdo con los resultados encontrados, es posible afirmar que los tiempos de reacción y las cantidades de TG son determinantes en los procesos de obtención de películas y geles de calidad, que pueden rendir mejores productos luego de la optimización de estos factores.
\end{abstract}

Palabras clave: Biopelículas; Propiedades reológicas; Transglutaminasa; Proteína de suero desnaturalizada.

\title{
1. Introdução
}

Amplamente utilizada como um ingrediente funcional na indústria de alimentos, a proteína do soro do leite é responsável por $20 \%$ da proteína total do leite e é um subproduto do processamento de queijos. Seus principais componentes incluem $\alpha$-lactalbumina, $\beta$-lactoglobulina, imunoglobulina e albumina sérica bovina (Jiang et al., 2020). Apresenta boas propriedades de emulsificação, espessamento, gelificação, retenção de água e formação de estrutura, sendo também facilmente digerida e absorvida pelo corpo humano, possuindo alto poder antioxidante, antiviral e outras atividades biológicas (Liang et al., 2020). Apesar de sua ampla utilização na formação de biofilmes, hidrogéis, dentre outros produtos, suas propriedades de viscosidade, emulsificação e gelificação precisam ser melhoradas.

A transglutaminase (TG) é uma enzima que usa o grupo $\gamma$-hidroxiamida do ácido glutâmico como o doador de acila e o grupo $\varepsilon$-amino da lisina como o aceitador de acila para causar reticulação covalente entre proteínas (ou polipeptídeos), formando assim a polimerização covalente (Jiang et al., 2020). Estudos recentes têm demonstrado que a reticulação de TG pode melhorar propriedades funcionais de proteínas alimentares, como a capacidade de retenção de água do gel, estabilidade térmica, propriedades emulsificantes e de viscosidade, dentre outras (Wang et al., 2020; Jiang et al., 2020).

No entanto, é necessário provocar a desnaturação do soro de leite, a fim de melhorar a acessibilidade da TG aos grupos de lisina e glutamina, proporcionando uma melhor reação de catalisação. De acordo com Cao et al., (2021) a proteína do soro do leite expõe mais resíduos de glutamina e lisina após o tratamento térmico (tipicamente maior que $65{ }^{\circ} \mathrm{C}$ ), fornecendo resíduos de glutamina e lisina acessíveis o suficiente para que a TG catalisasse a reticulação.

Diante disso, o estudo do comportamento reológico por meio da análise dos parâmetros reológicos no decorrer do tempo e variação da taxa de cisalhamento são imprescindíveis para a observação e compreensão da polimerização entre a TG e o soro de leite desnaturado (WPD), além de auxiliar em parâmetros de projeto futuros e controle das operações unitárias envolvidas no processo (Almeida et al., 2020). Neste contexto, o objetivo deste trabalho é realizar o estudo do comportamento reológico da reação de catalisação do soro de leite desnaturado (WPD) com a enzima transglutaminase microbiana (TG), em função dos tempos de reação e quantidade de TG.

\section{Metodologia}

Foram utilizados como matéria-prima o soro de leite em pó (Provon 292 IP) com 92\% de proteína, obtido pela empresa Homem da Terra. A enzima transglutaminase utilizada foi obtida pela empresa Gastrô Brasil, com atividade enzimática de $80 \mathrm{U} / g$. A água destilada foi utilizada para a preparação das soluções. 
A solução do soro de leite desnaturado (WPD) foi preparada pesando $25 \mathrm{~g}$ de soro de leite e dissolvendo em $500 \mathrm{ml}$ de água destilada, logo após a dissolução, a fim de promover o desdobramento da proteína, a solução foi aquecida a $70^{\circ} \mathrm{C}$ por 15 minutos e resfriada até $30^{\circ} \mathrm{C}$. Logo após o resfriamento, a enzima transglutaminase (TG) foi adicionada nas proporções de 8 , 14, 18, 22 e $26 \mathrm{U} / \mathrm{g}$. Todas as soluções de WPD+TG foram colocadas para reagir nos tempos de 8, 16 e 24 horas, para avaliação das suas propriedades reológicas.

Para avaliação das propriedades reológicas foram mensurados os valores de viscosidade e torque das amostras de WPD+TG utilizando um viscosímetro Brookfield (modelo DV-II + PRO, Brookfield Engineering Laboratories Inc., MA, EUA) em temperatura ambiente $\left(25 \pm 1^{\circ} \mathrm{C}\right)$ usando velocidades de rotação $(50,60,70,80,90,100,120,135,140,150,160$, 180 e $200 \mathrm{rpm}$ ) de acordo com a metodologia proposta por (Lima et al., 2018). Todos os dados foram coletados após $30 \mathrm{~s}$ em cada velocidade de rotação, nos intervalos de tempo propostos ( 8,16 e 24 horas). Os dados de torque, viscosidade e velocidade de rotação foram convertidos em taxas de deformação e tensão de cisalhamento usando o método proposto por (Mitschka, 1982).

O modelo reológico (Eq. 1) de Ostwald-de-Waelle (Lei de potência) foi ajustado aos valores experimentais de tensão de cisalhamento e da taxa de deformação, no qual, foi aplicado à análise de regressão não linear, pelo método Quasi-Newton, a partir do software Statistica 12.0 (Statsoft, 2012), para a realização do ajuste do modelo matemático aos dados experimentais.

$$
\tau=K \Upsilon^{n p}
$$

Em que: $\tau$ é a tensão de cisalhamento (kPa); K e np é o índice de comportamento do fluido (adimensional) e $\curlyvee$ é a taxa de deformação (1/s).

O critério de avaliação utilizado para melhor ajuste do modelo aos dados experimentais foi o coeficiente de determinação $\left(\mathrm{R}^{2}\right)$, calculado pela (Equação 2):

$$
\mathrm{R}^{2}=\Sigma(\text { Xobs }- \text { Xpre })^{2}
$$

Em que: Xobs é o valor experimental; Xpre é o valor previsto pelo modelo.

\section{Resultados e Discussão}

A Figura 1 apresenta a viscosidade dependente da taxa de deformação do whey protein desnaturado (WPD) com a adição de 8 U/g (Fig. A), 14 U/g (Fig. B), 18 U/g (Fig. C), 22 U/g (Fig. D) e 26 U/g de enzima transglutaminase microbiana (TG) (Fig. E), avaliando o comportamento do WPD + TG após 8, 16 e 24 horas de reação. A análise da Figura 1A revela que os valores de viscosidade do WPD+TG nas primeiras 8 horas de reação aumentam progressivamente com a taxa de deformação, este fato indicia que as alterações nas estruturas das proteínas do leite ocasionadas pela desnaturação, levam a uma maior agregação e ligação intermolecular, resultando no aumento da viscosidade da solução. Jiang et al., (2019) afirmam que a desnaturação térmica do soro de leite é caracterizada pela alteração de estruturas secundárias e terciárias, expondo os resíduos hidrofóbicos ao solvente, ocasionando uma exposição e ativação de grupos sulfidrila livres. 
Figura 1: Comportamento reológico das soluções tratadas com TG para reticulação com WPD adaptado à lei de OstwaldWaelle nos tempos de reação de 8,16 e 24 horas.
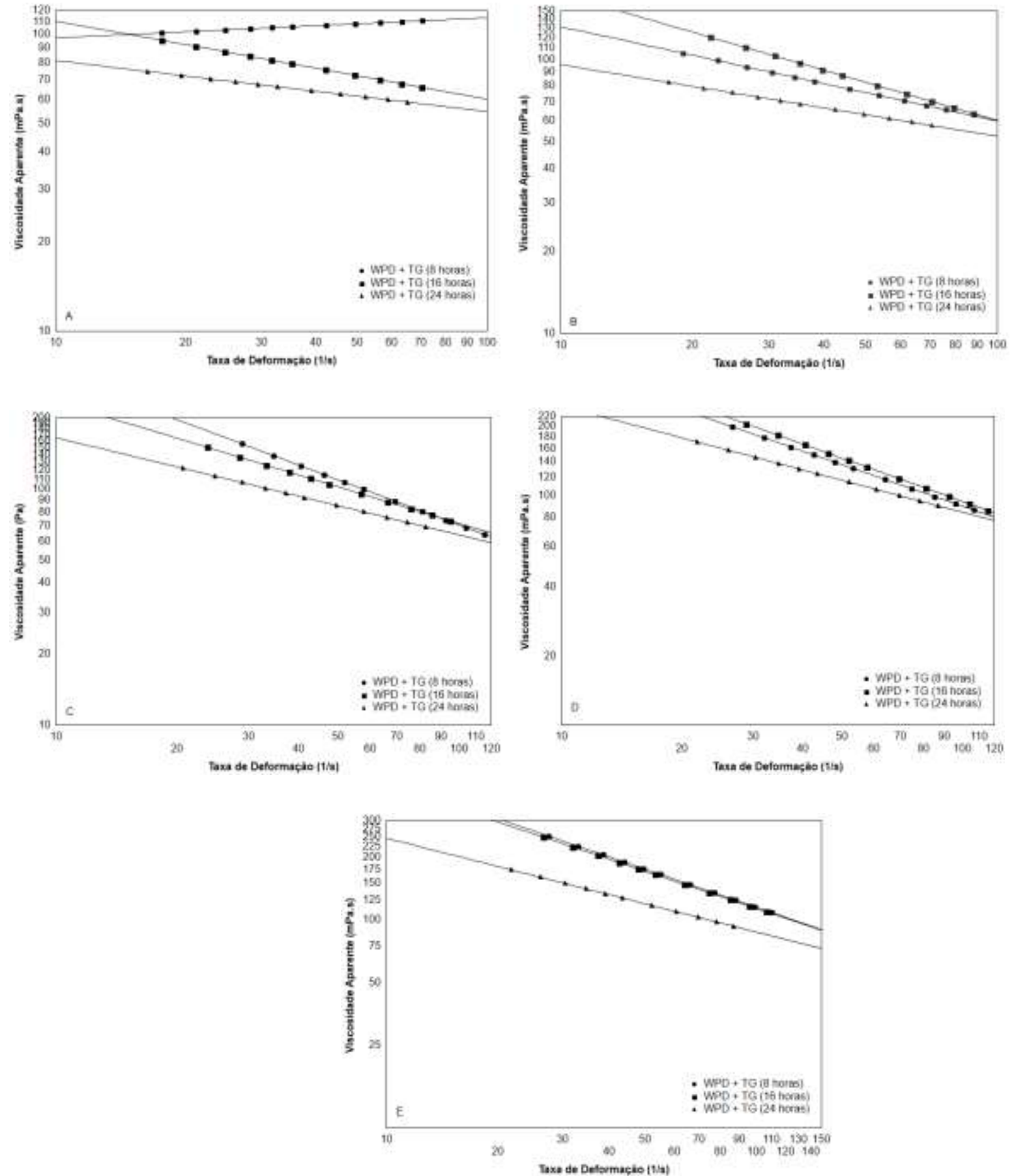

Fonte: Autores.

Entretanto após 16 horas de reação houve uma redução da viscosidade com o aumento da taxa de deformação nas demais amostras, caracterizando um comportamento pseudoplástico. Este comportamento geralmente é encontrado em soluções compostas por polímeros de alto peso molecular (Silva et al., 2020). Desta forma, sugere-se que com a adição da TG tenham sido formadas estruturas de alto peso molecular. Liang et al., (2020) afirma que o aumento da taxa de deformação pode levar a uma destruição parcial da rede de proteínas agregadas, reduzindo a resistência ao fluxo, diminuindo a viscosidade aparente. 
As curvas de fluxo das soluções de WPD e TG são apresentadas na Figura 2, a equação de Oswald-Waelle (lei de potência) foi usada para ajustar os dados. As amostras apresentaram o comportamento característico de soluções nãonewtonianas pseudoplásticas com aumentos progressivos na tensão de cisalhamento com a taxa de deformação.

Figura 2: Comportamento de fluxo das soluções tratadas com transglutaminase microbiana nas proporções de 8 U/g (Fig. A), 14 U/g (Fig. B), 18 U/g (Fig. C), 22 U/g (Fig. D) e 26 U/ g (Fig. E) e whey protein desnaturado ajustadas à lei de OstwaldWaelle nos tempos de reação de 8,16 e 24 horas.
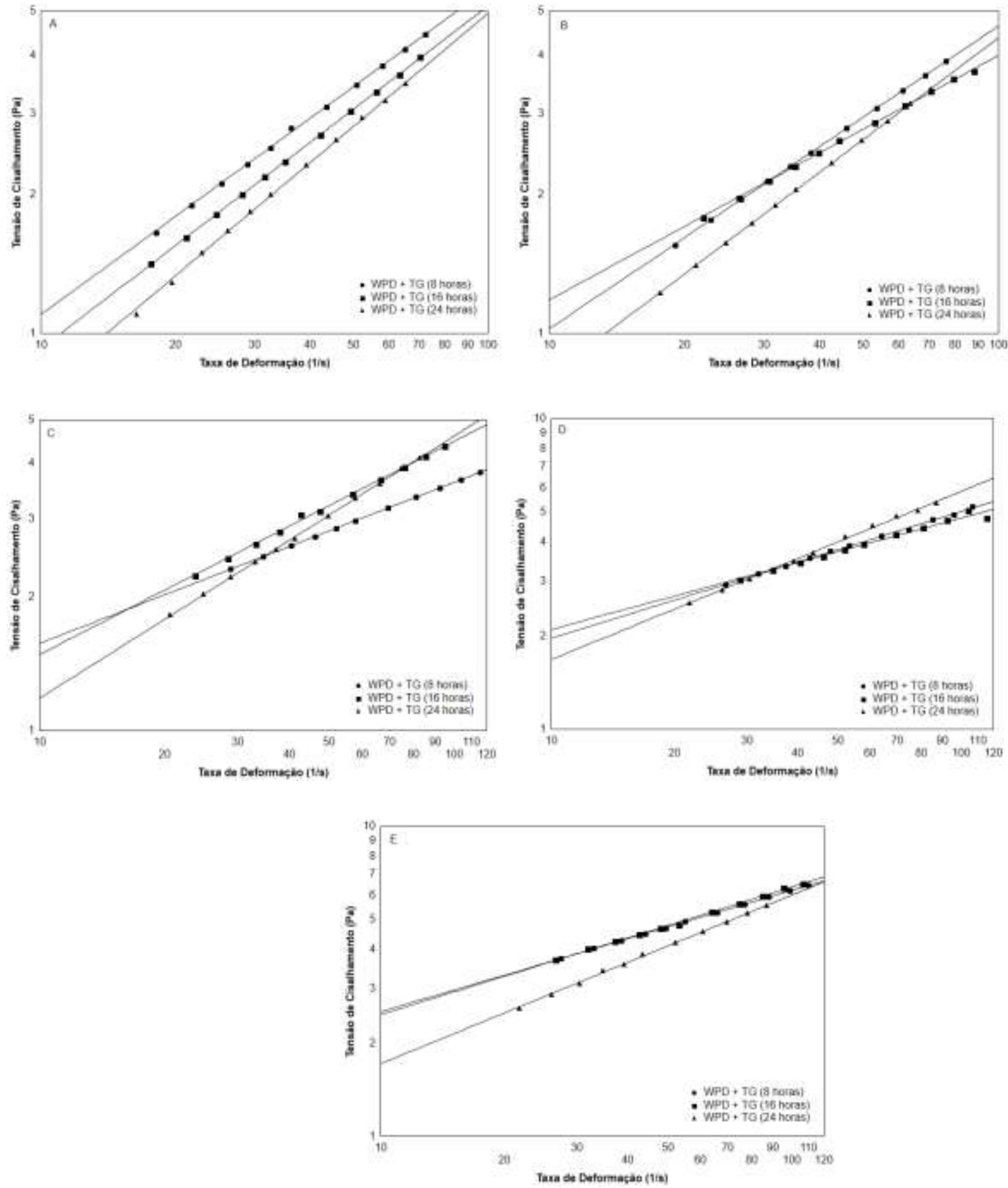

Fonte: Autores. 
Uma tendência é notada nas primeiras 8 horas de reação, quando a TG é adicionada ao WPD nas Figuras 2ª $2 \mathrm{~B}$ e 2C, ocorrendo uma diminuição da força de cisalhamento à medida que o TG é acrescentado, este fato provavelmente se deve ao tempo curto de reação, já que em tempos maiores ocorre uma estabilização da rede promovendo maiores forças de cisalhamento. Entretanto, as adições de 22 e 26 U/g de TG ilustradas nas Figuras 2D e 2E, promoveram maiores tensões e taxas de cisalhamento. É provável que a desnaturação proteica, provocou um desdobramento da proteína, promovendo uma maior exposição dos grupos amina, auxiliando na reticulação da TG com o WPD exigindo, portanto, maiores forças de cisalhamento nas soluções (Djoullah et al., 2018; Jiang et al., 2019). Este fato corrobora com os estudos de Wang et al., (2020), no qual o aumento da concentração de TG e do tempo de reação, proporcionam géis mais fortes, sendo submetidos à maiores forças de cisalhamento.

A Tabela 1 apresenta os valores do índice de consistência (K) e o índice de comportamento ( $\eta$ p), obtidos a partir dos ajustes das curvas de fluxo (Fig.2). Os resultados mostram que o modelo da lei de potência descreve com precisão o comportamento de fluxo dos tratamentos de WPD+TG, nos diferentes tempos de reação.

Tabela 1: Parâmetros dos dados ajustados pela lei de potência para os tratamentos de WPD+TG, com tempos de reação de 8, 16 e 24 horas.

\begin{tabular}{ccccc}
\hline \multirow{2}{*}{ TG } & \multirow{2}{*}{ Tempo de reação } & \multicolumn{2}{c}{ Parâmetros } & \multirow{2}{*}{$\mathbf{R}^{2}$} \\
\cline { 3 - 4 } & 8 horas & 0,708 & 0,216 & 0,999 \\
\multirow{2}{*}{ 8 U/g de WP } & 16 horas & 0,744 & 0,168 & 0,999 \\
& 24 horas & 0,814 & 0,117 & 0,999 \\
\hline \multirow{2}{*}{14 U/g de WP } & 8 horas & 0,657 & 0,225 & 0,999 \\
& 16 horas & 0,531 & 0,348 & 0,999 \\
& 24 horas & 0,733 & 0,149 & 0,999 \\
\hline \multirow{2}{*}{18 U/g de WP } & 8 horas & 0,362 & 0,682 & 0,999 \\
& 16 horas & 0,479 & 0,491 & 0,998 \\
& 24 horas & 0,591 & 0,303 & 0,999 \\
\hline \multirow{2}{*}{22 U/g de WP } & 8 horas & 0,409 & 0,767 & 0,997 \\
& 16 horas & 0,358 & 0,917 & 0,977 \\
& 24 horas & 0,542 & 0,482 & 0,997 \\
\hline \multirow{2}{*}{ 26 U/ g de Wp } & 8 horas & 0,391 & 1,02 & 0,999 \\
& 16 horas & 0,411 & 0,957 & 0,998 \\
& 24 horas & 0,543 & 0,491 & 0,999 \\
\hline
\end{tabular}

Fonte: Autores.

A adição de TG proporcionou um aumento no índice de consistência do WPD reticulado por TG em todos os tempos de reação. Além disso, com o tempo de reação variando entre 8, 16 e 24 horas, o índice de consistência do reticulado WPD + TG diminuiu, enquanto o índice de comportamento de fluxo aumentou. Sugere-se que a reação catalisada pela TG ocasiona a formação de polímeros de alto peso molecular devido as ligações intra e intermoleculares entre as moléculas de proteína. Ahmadi et al., (2017) reportaram que as pontes de reticulação podem levar a valores de k mais altos, sendo resultado da reticulação com TG. Além disso, os autores ressaltam que a adição da enzima em concentrações acima de 50 U/g não aumentará o valor de $\mathrm{k}$, permanecendo constante. 
De acordo com Gauche et al., (2008) o índice de comportamento de fluxo ( $\eta$ p) reflete a proximidade do fluido a um comportamento newtoniano. Quando $\eta \mathrm{p}=1$, o fluido é considerado newtoniano; na aproximação de $\eta \mathrm{p}=0$, o fluido é considerado pseudoplástico. A diminuição do índice de comportamento do fluxo ocorre quando a TG é adicionada, provavelmente o desdobramento da proteína provocado pela desnaturação, diminuiu o numero de espaços vazios no aglomerado formado através da reticulação com a mTgase, dificultando a capacidade de cisalhamento e comprometendo o fluxo das soluções devido aos emaranhados.

Entretanto, é possível observar que o $\eta$ p aumenta progressivamente com o tempo de reação, a explicação deste fato pode estar associada a um possível aumento de solubilidade da solução WPD + TG, levando a uma solução newtoniana, aproximando os valores de $\eta$ p a 1. Lima et al., 2018 reportaram que o aumento do movimento da corrente resulta em resistência semelhante ao fluxo em taxas de cisalhamento baixas ou altas.

\section{Conclusão}

A adição da enzima transglutaminase (TG) pode alterar as propriedades de viscosidade quando adicionada ao soro de leite desnaturado (WPD) promovendo a reticulação e formação de géis com maior resistência às forças cisalhantes, entretanto, a eficiência da polimerização depende do tempo em que a solução do WPD+TG está reagindo. O modelo reológico de Ostwald-de-Waele apresentou bons ajustes aos dados experimentais com valores de $\mathrm{R}^{2}$ acima de 0,99 . Com valores de $\eta \mathrm{p}<1$, as soluções de WPD+TG apresentaram comportamento de fluido pseudoplástico, no qual ocorreram aumentos progressivos nas taxas de deformação e tensões de cisalhamento.

\section{Agradecimentos}

Os autores agradecem ao Conselho Nacional de Desenvolvimento Científico e Tecnológico (CNPq) pelo apoio financeiro.

\section{Referências}

Ahmadi, S., Razavi, S. M. A., Varidi, M. (2017). Sequential ultrasound and transglutaminase treatments improve functional, rheological, and textural properties of whey protein concentrate. Innovative Food Science and Emerging Technologies. 43, 207-215. http://dx.doi.org/10.1016/j.ifset.2017.08.013

Almeida, R. L. J., Santos, N. C., Pereira, T dos. S., Silva, V. M de. A., Ribeiro, V. H de. A., Silva, L. N., Muniz, C. E de. S., Silva, L. R. I da., Moreira, F. I. N., Monteiro, Y. G. (2020). Estudo reológico da polpa de Jabuticaba com diferentes concentrações de goma arábica. Research, Society and Development. 9 (3), 1-13. http://dx.doi.org/10.33448/rsd-v9i3.2511

Cao, C., Feng, Y., Kong, B., Sun, F., Yang, L., Liu, Q. (2021). Transglutaminase crosslinking promotes physical and oxidative stability of filled hydrogel particles based on biopolymer phase separation. International Journal of Biological Macromolecules. 172, 429-438. https://doi.org/10.1016/j.ijbiomac.2021.01.073

Djoullah, A., Husson, F., Saurel, R. (2018). Gelation behaviors of denaturated pea albumin and globulin fractions during transglutaminase treatment. Food Hydrocolloids. 77, 636-645. https://doi.org/10.1016/j.foodhyd.2017.11.005

Gauche, C., Vieira, J. T. C., Ogliari, P. J., Bordignon-Luiz, M. T. (2008). Crosslinking of milk whey proteins by transglutaminase. 43(7), 788-794. https://doi.org/10.1016/j.procbio.2008.04.004

Jiang, S., Zou, L., Hou, Y., Qian, F., Tuo, Y., Wu, X., Zhu, X., Um, G. (2020). The influence of the addition of transglutaminase at different phase on the film and film forming characteristics of whey protein concentrate-carboxymethyl chitosan composite films. Food Packaging and Shelf Life. 25(100456), 1-8. https://doi.org/10.1016/j.fpsl.2020.100546

Jiang, Z., Whang, C., Li, T., Sun, D., Gao, Z., Mu, Z. (2019). Effect of ultrasound on the structure and functional properties of transglutaminase-crosslinked whey protein isolate exposed to prior heat treatment. International Dairy Journal. 88, 79-88. https://doi.org/10.1016/j.idairyj.2018.08.007

Liang, X., Ma, C., Yan, X., Zeng, H., McClements, D. J., Liu, X., Liu, F. (2020). Structure, rheology and functionality of whey protein emulsion gels: Effects of double cross-linking with transglutaminase and calcium ions. Food Hydrocolloids. 102(105569), 1-11. https://doi.org/10.1016/j.foodhyd.2019.105569

Lima, D. B., Almeida, R. D., Pasquali, M., Borges, S. P., Fook, M. L., Lisboa, H. M. (2018). Physical characterization and modeling of chitosan/peg blends for injectable scaffolds. Carbohydrate Polymers. 189, 238-249. https://doi.org/10.1016/j.carbpol.2018.02.045 
Research, Society and Development, v. 10, n. 7, e14310716447, 2021 (CC BY 4.0) | ISSN 2525-3409 | DOI: http://dx.doi.org/10.33448/rsd-v10i7.16447

Mitschka, P (1982). Simple conversion of brookfield RVT: readings into viscosity functions

Silva, H. A., Paiva, E. G., Lisboa, H. M., Duarte, M. E. M., Mata, M. C. M., Gusmão, T. A. S., Gusmão, R. P. S. (2020). Role of chitosan and transglutaminase on the elaboration of gluten-free bread. Journal of Food Science and Technology. 57, 1877-1886. https://doi.org/10.1007/s13197-019-04223-5

Statsoft (2012), Inc. Statistica for Windows (data analysis softwaresystem), version 12.0. Computer program manual.Tulsa: Statsoft.

Wang, C., Li, T., Ma, L., Li, T., Yu, H., Hou, J., Jiang, Z. (2020). Consequences of superfine grinding treatment on structure, physicochemical and rheological properties of transglutaminase-crosslinked whey protein isolate. Food Chemistry. 309(125757), 1-8. https://doi.org/10.1016/j.foodchem.2019.125757 